\title{
A Lack of "Environmental Earth Data" at the Microhabitat Scale Impacts Efforts to Control Invasive Arthropods That Vector Pathogens
}

\author{
Emily L. Pascoe ${ }^{1, *}$, Sajid Pareeth ${ }^{2}$, Duccio Rocchini ${ }^{3,4,5,6}$ and Matteo Marcantonio $7, *$ (D) \\ 1 Department of Medicine and Epidemiology, School of Veterinary Medicine, University of California, \\ Davis, CA 95616, USA \\ 2 Water Science and Engineering Department, IHE Delft Institute for Water Education, \\ 2611AX Delft, The Netherlands; s.pareeth@un-ihe.org \\ 3 Center Agriculture Food Environment (C3A), University of Trento, Via E. Mach 1, \\ 38010 S. Michele all'Adige, TN, Italy; duccio.rocchini@unitn.it \\ 4 Department of Cellular, Computational and Integrative Biology (CIBIO), University of Trento, \\ Via Sommarive, 14, 38123 Povo, TN, Italy \\ 5 Department of Biodiversity and Molecular Ecology, Fondazione Edmund Mach, \\ Research and Innovation Centre, Via E. Mach 1, 38010 S. Michele all'Adige, TN, Italy \\ 6 Department of Applied Geoinformatics and Spatial Planning, Faculty of Environmental Sciences, \\ Czech University of Life Sciences Prague, Kamýcka 129, Praha-Suchdol 16500, Czech Republic \\ 7 Department of Pathology, Microbiology, and Immunology, School of Veterinary Medicine, \\ University of California, Davis, CA 95616, USA \\ * Correspondence: elpascoe@ucdavis.edu (E.L.P.); matmarcantonio@ucdavis.edu (M.M.)
}

Received: 27 May 2019; Accepted: 19 September 2019; Published: 29 September 2019

\begin{abstract}
We currently live in an era of major global change that has led to the introduction and range expansion of numerous invasive species worldwide. In addition to the ecological and economic consequences associated with most invasive species, invasive arthropods that vector pathogens (IAVPs) to humans and animals pose substantial health risks. Species distribution models that are informed using environmental Earth data are frequently employed to predict the distribution of invasive species, and to advise targeted mitigation strategies. However, there are currently substantial mismatches in the temporal and spatial resolution of these data and the environmental contexts which affect IAVPs. Consequently, targeted actions to control invasive species or to prepare the population for possible disease outbreaks may lack efficacy. Here, we identify and discuss how the currently available environmental Earth data are lacking with respect to their applications in species distribution modeling, particularly when predicting the potential distribution of IAVPs at meaningful space-time scales. For example, we examine the issues related to interpolation of weather station data and the lack of microclimatic data relevant to the environment experienced by IAVPs. In addition, we suggest how these data gaps can be filled, including through the possible development of a dedicated open access database, where data from both remotely- and proximally-sensed sources can be stored, shared, and accessed.
\end{abstract}

Keywords: arthropod vector; invasive species; microhabitat; species distribution modeling; remote sensing

\section{Introduction}

In an era of major global change (i.e., in climate, land use, habitat fragmentation, and movements of humans and other species) the introduction of invasive species and the geographic expansion 
of endemic species to novel ranges are occurring at unprecedented rates [1,2]. Invasive species have extensive negative impacts on the ecosystems they invade, such as losses in both taxonomic and functional diversity [3], resulting in severe economic consequences. For example, in the USA invasive insects cost the agricultural sector USD 13 billion per year due to crop loss and damage [4], routine activities to control Aedes mosquitoes in Cuba cost USD 16.80 per household [5], and Great Britain spends USD 34.6 million per year on the control of invasive fresh-water species [6]. The stakes are even higher when invasive species can vector pathogens that cause disease in humans, animals, or plants. Some arthropod species that are highly invasive are among the most effective vectors of human pathogens. Mosquitoes, such as Aedes aegypti [Linneaus, 1762] and Aedes albopictus [Skuse, 1895], are invasive arthropods able to vector pathogens (henceforth referred to as IAVPs) and transmit three globally important viruses to humans: chikungunya, dengue, and Zika [7]. Likewise, the Asian longhorned tick Haemaphysalis longicornis [Neumann, 1901], which is rapidly expanding across the east coast of the USA [8], can vector the severe fever and thrombocytopenia syndrome virus, which has human fatality rates exceeding $30 \%$ in Asia [9]. Of veterinary importance, the biting midge Culicoides imicola [Kieffer, 1913] is currently expanding in range throughout Europe and can transmit the bluetongue and African horse sickness viruses [10]. Plants are also affected, cotton whiteflies (Bemisia species, including Bemisia tabaci [Gennadius, 1889]), now present in every continent except Antarctica, can transmit over 100 different plant viruses [10].

In order to prevent the potentially catastrophic ecological, economical, and health consequences associated with IAVPs, mitigation methods must be rapidly employed following species introduction or expansion into a new geographical range [11]. Mitigation methods may include IAVP control and eradication, or communication of the risks to policy makers, physicians and the public, and environmental data are often used to inform these different processes. Here, we describe the benefits and limitations associated with using i) remotely sensed data, which we define as data acquired by sensors mounted on satellite, airborne, or other distant means, and ii) proximally sensed data, which we define as having been collected by a ground-based, or other platform, in close proximity to the variable being measured, in order to inform IAVP mitigation.

\section{Linking Environmental Earth Data and IAVPs}

As observed by Malanson and Walsh; "detection and eradication [of invasive species] are essentially spatial problems. They primarily require learning where the invasives are and getting there" [12]. This is a simplification of a more complex issue, which may also involve a lack of personnel or funding to efficiently implement detection and eradication, insufficient communication or perception of the IAVP risk, and even IAVP resistance to control measures. However, environmental data can be used to address the "spatial problems" by informing predictions on where invasive species may be introduced and become established.

In some instances, using environmental data in the mitigation of an invasive species can be as straightforward as directly detecting the species. For example, thanks to the reflectance properties of vegetation, invasive plants can be mapped using indices such as NDVI (the Normalized Difference Vegetation Index) or EVI (the Enhanced Vegetation Index) that are derived from remotely sensed data that measures infrared reflectance (e.g., in [13], and also see [14] for a review on this method). A similar concept can be applied to invasive arthropods which cause damage to vegetation, and NDVI data has been used to track the dispersal of invasive insects by monitoring defoliation [15,16]. Although weather radars have detected mass migrations of invasive insects [17], as yet remotely sensed data cannot directly characterize IAVP geographical distributions. There are promising proximal sensing methods that use reflectance data from cameras that can detect and differentiate between multiple fruit fly species, including those that vector crop pathogens [18] (see also [19] for an interesting application of proximal sensing of an invasive pathogenic plant bacterium). However, mapping IAVP distribution in real-time is often less desirable than preempting the potential geographic distribution, as surveillance and control are more efficient if implemented prior to the establishment of a species $[11,12,20]$. 
Species distribution models (SDMs) are frequently used to predict the current and future geographic distribution of IAVPs $[11,12,20]$ due to their ability to be applied to species that cannot be directly detected because they are small, elusive or inhabit remote locations. Typically, correlative SDMs apply an algorithm, such as maximum entropy, boosted regression trees or random forest, that combines empirical occurrence data on the species with relevant environmental data (e.g., average temperature and precipitation) to predict the spatial and temporal distributions of a species [21,22]. Mechanistic models, such as compartmental or agent-based models have also been developed, alone or in combination with correlative models, to characterize potential species distributions [23,24]. Here, we adopt a broad definition of SDMs to include any modeling approach that aims to predict the distribution of a species, from logistic regression to multi-criteria decision analyses. In the last few decades there has been a sharp increase in the number of publications on SDMs, with hundreds published each year [25]. This dramatic rise in interest in SDMs is in part due to advances in remote sensing technology, including new satellites and sensors that have hugely increased the quantity and quality of environmental data that can be used [26].

\section{Gathering Environmental Data for SDMs}

The accuracy of SDM predictions is highly dependent on how closely the data used in the model match conditions relevant to the species and, despite considerable increases in both spatial and temporal resolution of available environmental data, there is often still a substantial mismatch in the conditions represented by the available data and those experienced by IAVP species. Environmental data used in SDMs can be classified as bio-physical or climatic, both of which can be measured by proximal sensing, but data used in SDMs is typically derived from remote sensing.

\subsection{Bio-Physical Variables}

Bio-physical variables generally include land-use, land cover, primary productivity, and vegetation phenology and fragmentation. Bio-physical variables are almost exclusively derived from Earth observation satellites which measure either reflectance at various wavelengths in the electromagnetic spectrum, or emitted radiances in the thermal spectrum. These reflectance data can be used to calculate NDVI and NDWI (Normalized Difference Water Index), which are applied instead of, or alongside, other satellite imagery/reflectance data to ascertain variables such as land-use and land cover (Table 1). Satellite data are available in a wide range of spatial ( $<1 \mathrm{~m}$ to $>5 \mathrm{~km}$ ) and temporal (hourly to yearly) resolutions, and allow for some user flexibility based on the scale at which the model is applied (e.g., eco-region, county, national, global). Given technological limitations due to on-board storage media or limited opportunity for data transmission, spatial and temporal resolution of remote sensing tools are inversely correlated [27]. As the majority of bio-physical variables remain static or exhibit very gradual changes over time, spatial resolution is often prioritized over temporal resolution. For example, since 1972 the NASA-USGS Landsat series has provided uninterrupted data on the Earth's surface at a relatively high resolution of $30 \mathrm{~m}$, but measurements are only taken once every 16 days, although this will increase to every eight days starting from 2020. NOAA VIIRS provides a series of environmental data, as well as monthly cloud-free composites of visible infrared emittance for the entire Earth during night at a resolution of $15 \operatorname{arcsec}(<500 \mathrm{~m}$ at the equator) [28], which can be used as a proxy for human settlements to inform the possible human contact risk associated with IAVP presence $[29,30]$. Since the 1980 's, satellite remote sensors such as AVHRR and, many years later, MODIS, have allowed the derivation of more spatially and temporally continuous vegetation and surface temperature data at a moderate spatial resolution (250-1000 m), but with more frequent (daily) observations, thus greatly enriching the available datasets [31]. In addition, the more recent Sentinel missions $(2 \mathrm{~A}, 2 \mathrm{~B}, 3)$ from the European Space Agency (ESA) have offered optical data at 10-300 m spatial resolution every 3-7 days since 2016. 
Table 1. A summary of the main sources of environmental data that can be used in species distribution modeling of invasive species that vector pathogens, including information on the environmental variables that can be derived from the data, spatial and temporal resolution, and the geographic extent that the data are able to cover.

\begin{tabular}{|c|c|c|c|c|c|}
\hline Mission/Sensor & Type of Sensing & Environmental Variables for IAVPs & Spatial Resolution & Temporal Grain and Extent & Extent \\
\hline NASA-MODIS & Multi-satellite & NDVI, NDWI, LST, Land cover & $0.25-1 \mathrm{~km}$ & 4-times/day [2001-present] & Global \\
\hline NASA-USGS Landsat series & Multi-satellite & NDVI, NDWI, imagery & $30 \mathrm{~m}$ & $16 \mathrm{~d}$ [1972-present] & Global \\
\hline ESA SENTINEL missions & Multi-satellite & NDVI, NDWI, LST, imagery & $10-300 \mathrm{~m}$ & 3-10 d [2015-present] & Global \\
\hline NOAA VIIRS & Multi-satellite & $\begin{array}{l}\text { NDVI, NDWI, LST, imagery, } \\
\text { human settlements }\end{array}$ & $375-750 \mathrm{~m}$ & $1 \mathrm{~d}$-monthly [2015-present] & Global \\
\hline $\begin{array}{l}\text { Global Precipitation Measurement } \\
\text { Mission (GPMM) }\end{array}$ & Multi-satellite & Precipitation & $11 \mathrm{~km}^{*}$ & 2-3 h [2015-present] & Global (65S-65N) \\
\hline $\begin{array}{l}\text { Tropical Rainfall Measuring } \\
\text { Mission (TRMM) }\end{array}$ & Multi-satellite & Rainfall & $28 \mathrm{~km}^{*}$ & $3 \mathrm{~h}-7 \mathrm{~d}$ [1998-2015) & Tropical and sub-tropical regions \\
\hline USDA-NAIP & Airborne & NDVI, imagery & $60 \mathrm{~cm}-1 \mathrm{~m}$ & $\begin{array}{c}\text { "Snapshot" every } 3 \text { years } \\
\text { [2003-present] }\end{array}$ & Mainland USA (variable coverage) \\
\hline Dataset Name & Ancillary Data & Environmental Variables for IAVPs & Spatial Resolution & Temporal Grain and Extent & Extent \\
\hline WordClim & Weather station & $2 \mathrm{~m}$ air temperature and precipitation & $1 \mathrm{~km}^{*}$ & LTA 1950-2000 & Global \\
\hline MODIS Land Cover Type/Dynamics & Satellite & Land cover & $0.5-1 \mathrm{~km}$ & Yearly/twice a year [2001-present) & Global \\
\hline Copernicus Land Cover & $\begin{array}{l}\text { Multi-satellite (SPOT, } \\
\text { PROBA-V, Sentinel-2) }\end{array}$ & Land cover & $100 \mathrm{~m}$ & Multi-year [2015-present) & Global \\
\hline USGS Land Cover maps & $\begin{array}{l}\text { Satellite (Landsat) and } \\
\text { geospatial ancillary datasets }\end{array}$ & Land cover/impervious surface & $30 \mathrm{~m}$ & Multi-year [2001-present] & Continental US \\
\hline CORINE Land Cover maps & $\begin{array}{l}\text { Multi-satellite (Landsat, SPOT, } \\
\text { IRS, RapidEye, Sentinel-2) }\end{array}$ & Land cover & $100 \mathrm{~m}$ & Multi-year [1990-present] & Extended EU \\
\hline PRISM Climate data & Weather station & $\begin{array}{l}\text { Air temperature, precipitation, vapor } \\
\text { pressure, day length }\end{array}$ & $0.8-4 \mathrm{~km}$ & Daily [1895-**) & Continental US \\
\hline $\begin{array}{l}\text { Daily Surface weather and } \\
\text { climatological summaries (DAYMET) }\end{array}$ & Weather station & $\begin{array}{l}\text { Air temperature, precipitation, vapor } \\
\text { pressure, day length }\end{array}$ & $1 \mathrm{~km}$ & Daily [1980-present calendar year] & North America, Puerto Rico and Hawaii \\
\hline
\end{tabular}

${ }^{*}$ Approximate spatial resolution in metric unit of lengths on the equator, ${ }^{* *} 6$ months from current date. 
The accuracy of satellite data is generally strongly linked to the method of derivation, geographical region, climatic condition, and availability of in-situ data for calibration, which in turn affect SDM results. For example, cloud cover often hinders satellite optical data, especially in inter-tropical regions, but there are multiple statistical approaches that can fill these gaps over space or time [32]. Remotely sensed data on bio-physical Earth observations can be combined with ground-based (in-situ) data to provide crucial information on habitat structure, and are therefore commonly used in SDMs. Large extent datasets for bio-physical variables, such as the Global Copernicus Land Cover maps (spatial resolution $=100 \mathrm{~m}$ ) [33], the pan-European Corine Land Cover $(100 \mathrm{~m})$ [34], the USA National Land Cover Datasets (30 m) [35] and the global MODIS Land Cover Type/Dynamics (500 m-1 km) [36], are derived using a combination of satellite and ground (in-situ) sensors [35]. However, these data are typically presented as a single multi-annual "snapshot" using a composite of several observations over time, and thus, provide very limited information on temporal variation.

\subsection{Climatic Variables}

Climatic data, which is often fundamental in the physiology of arthropods, includes variables such as land surface temperature (LST) or air temperature and precipitation. Such data are commonly derived from remote sensing and are frequently used in SDMs. Precipitation can be measured by active satellite sensors in the micro-wave region and offer high temporal (hourly) but coarse spatial resolution data (e.g., GPM and TRMM; Table 1). As for bio-physical variables, the spatial and temporal resolution of satellite data for climatic variables are also inversely related, which results in a lack of high spatial resolution data at higher temporal frequencies of measurement. In the case of climatic variables, which can vary minute-by-minute, temporal resolution is highly important. This trade-off often plays a significant role in attaining high accuracy results from SDMs. To fill these temporal gaps, recent satellite missions that measure radiance in the thermal spectrum bands (i.e., which measure temperature) are focused on providing higher spatial resolution climatic data with frequent measurements (e.g., Sentinel $2 \mathrm{~A} / \mathrm{B}$ data at $10 \mathrm{~m}$ with weekly acquisitions).

In addition to satellite-derived Earth data, data collected by ground-based weather stations, or a combination of both, such as the WorldClim, PRISM, Daymet and ECA\&D datasets, are perhaps the most widely used climatic data in SDMs due to the user friendly format that requires comparatively little pre-processing compared with satellite data (e.g., [37-42]). As weather stations measure variables at discrete geographic locations these data must be interpolated to create a continuous spatial layer before being used in SDMs. There are multiple methods by which weather station data can be interpolated, but all are limited by the density of weather stations in the study area, and are confounded by topographical features and spatial gradients, although satellite or other remotely sensed data can help to remedy some of these shortcomings $[37,43,44]$.

For regional SDM applications high resolution datasets are required, but the availability of such data remains a challenge also for current satellite missions, despite considerable improvements during the last few years with the advent of the new Landsat and Sentinel missions.

\section{Issues Faced When Using Environmental Data in IAVP Models}

As described, there are many environmental datasets available that can inform SDMs. However, these datasets are often of limited relevance in the context of IAVP modeling, not least due to substantial mismatches between the spatial resolution at which predictions are made and the resolution at which the predictions are interpreted, communicated or applied. The spatial resolution of model predictions are constrained by the resolution of the environmental data used, which is typically in the order of kilometers. However, the subsequent predictions are often used to inform actions applied at spatial scales in the order of meters, such as informing which neighborhoods should be targeted for surveillance and control, where to install deer fences to control tick abundances, or communicating IAVP presence. Although some inaccuracies in SDM outputs may seem trivial in the context of a scientific paper, they can pose a serious issue when accurate predictions are required for use in 
"real world" scenarios. For example, SDMs and model-derived data are used by the Centers for Disease Control and Prevention (CDC) in the USA to inform administrative regions on the likelihood of Aedes mosquito invasion, in order to distribute vector control resources (e.g., intensive surveillance and insecticide application) [45,46]. Consequently, disparities between the spatial resolution of the data used to inform the model and that at which model outputs are applied will result in model outputs that are inaccurate for their intended applications. At best, IAVP distributions may be over-estimated, leading to unnecessary use of resources, and at worst, distributions can be underestimated such that no, or insufficient, actions are employed to control IAVPs in an area that is actually at risk. Indeed, an economic evaluation of biological invasions states that "uncertainty prevails concerning what ecosystems will be invaded and what impacts an invasion will have within these ecosystems", highlighting that accurate ecological and economic analyses are crucial in the allocation of finite resources to control invasive species [47].

There is also a mismatch in spatial resolution between environmental data used in SDMs, and that at which the IAVP is affected. Indeed, many arthropods, such as mosquitoes and ticks are small and poikilothermic, and are therefore heavily affected by microclimatic conditions, which vary at fine spatial scales (in the order of centimeters to meters) and differ to the surrounding macroclimatic conditions [48-50]. For example, potentially invasive ticks, especially nidicolous (nest-dwelling) species, spend almost their entire life-cycle within a limited spatial radius; following a bloodmeal they detach from the host and remain within the host's nest or a nearby sheltered area, such as a cave or crevice, in order to metamorphose [51]. Within these isolated and sheltered microhabitats environmental conditions can be very different to those in the surrounding environment. In the same way, IAVPs can be sensitive to extreme environmental conditions, for example the lone star tick (Amblyomma americanum [Linnaeus, 1758]), which is invasive across much of the north east of the USA, dies within just $2 \mathrm{~h}$ of exposure to temperatures of $\leq-3^{\circ} \mathrm{C}$ in the laboratory [52] and rapidly desiccates when exposed for several hours to temperatures exceeding $30^{\circ} \mathrm{C}$ [53]. Likewise, mortality of Culicoides brevitarsis [Kieffer, 1917] (Diptera: Ceratopogonidae), a vector of the bluetongue virus, is high in the laboratory when temperatures are greater than $35^{\circ} \mathrm{C}$, even if just for a few days [54]. Consequently, high temporal resolution of data is required to accurately capture the variance and range in environmental variables [44], but at present the most accessible remotely sensed data are only available for 1-6 day interval measurements, thus do not capture data at the same hourly temporal resolution that can affect IAVP survival. There is a wealth of literature demonstrating that if species were theoretically subjected to the macroclimate as measured by remote sensing, rather than the microclimate which they truly experience, their behavior, reproduction, growth, survival, and both phenotypic and genotypic adaptations would all be profoundly impacted [55].

In addition to issues of resolution in environmental data, some factors that impact IAVP distribution cannot be directly measured, and instead other measurements are used as a proxy, or are interpolated, for the variable of interest. Due to its importance in the IAVP life cycle, temperature is among the most broadly applied variables in IAVP species distribution modeling. However, land surface temperature is generally used as a proxy for ambient temperature [27,56,57], whilst relative humidity, which is vital to arthropod survival, is often calculated from temperature and dew point measurements, or minimum day-time air temperature [58]. SDMs are made further complex when the species of interest has multiple life stages, each of which may exploit a different microhabitat. Mosquitoes have an "amphibious" life history, throughout which they experience air, below-water, and water-surface temperatures, by having terrestrially fixed or floating eggs, aquatic immature larvae and flying adults [59]. Researchers have measured air temperature, water temperature, and precipitation to understand whether air temperature, usually used to determine mosquito distribution or life cycle, provides an appropriate direct measure for determining Anopheles [Diptera: Culicidae] larval development in water [48]. The authors of one such study concluded that their results "suggest that although widely used, air temperature alone does not provide an appropriate variable for estimating immature mosquito development or for setting threshold temperatures". Another study that measured temperature in microhabitats suitable for Aedes mosquitoes found that 
when utilizing temperature from remote sensors or weather stations instead of from proximal data loggers, model outputs predicted that Ae. albopictus developmental rates were delayed and population growth rates were under-estimated (Figure 1) [60]. Thus, the environmental characteristics important to the survival of an IAVP vary considerably compared to those that can be measured or interpolated by currently available data $[59,61]$, and the obliged use of sub-optimal proxy data may result in erroneous model outputs $[48,61]$.

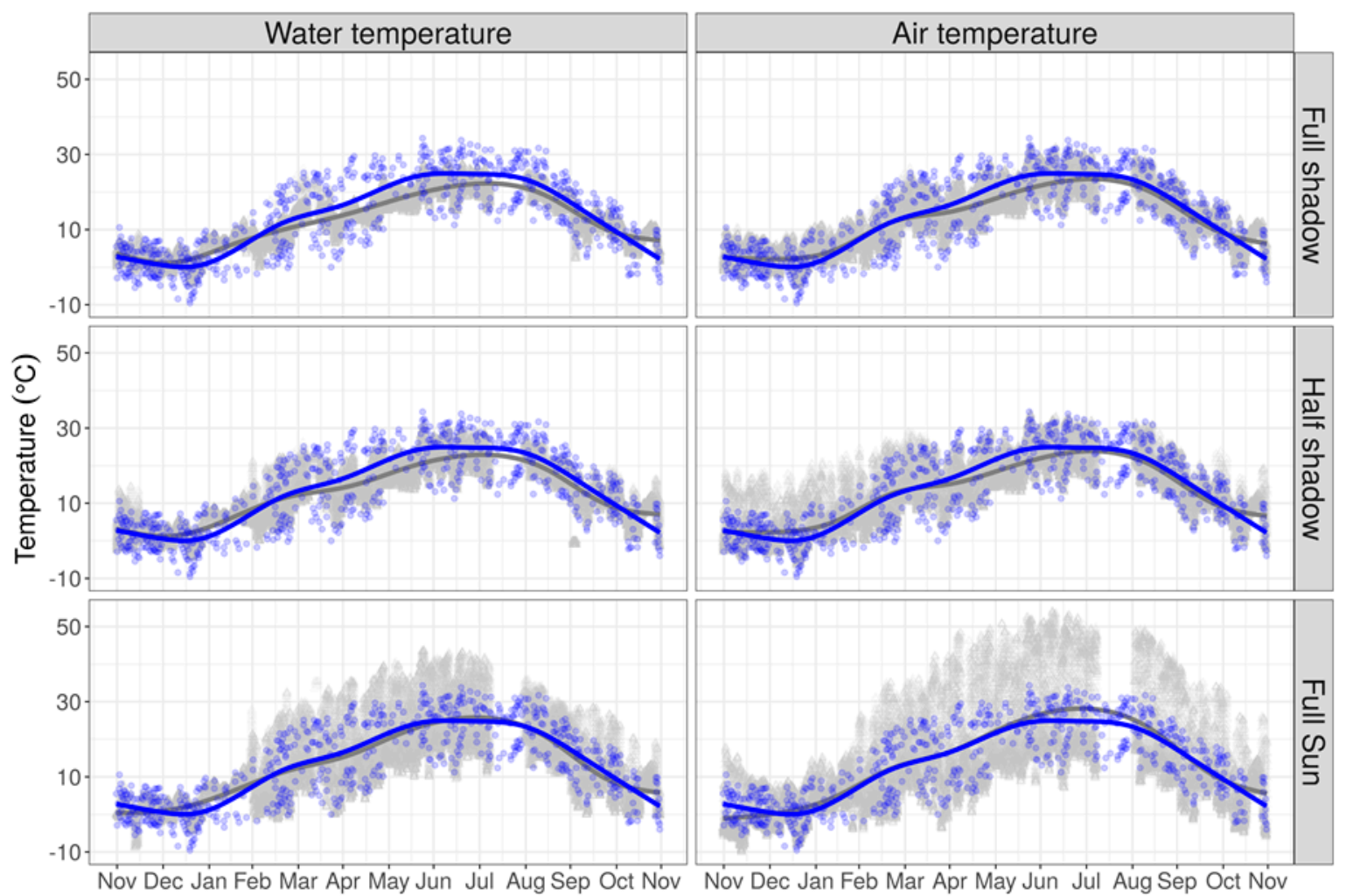

Figure 1. Temperature time series in an area invaded by Aedes albopictus mosquitoes in Italy $\left(11.13^{\circ} \mathrm{N}\right.$, $\left.46.2^{\circ} \mathrm{E}\right)$. Grey points and smoothed trends represent temperature measured at the microhabitat scale (i.e., an artificial, hard plastic, water filled container typically used for egg laying by this species) in different environmental settings: full-shadow, half-shadow, and full sun conditions. Temperatures were recorded inside (mosquito larvae habitat) and outside water (mosquito adult and egg habitat) using iButton ${ }^{\circledR}$ (Maxim Integrated, US) DS1923 data loggers at one hour intervals. Blue points and smoothed trends depict four-daily Land Surface Temperature (LST; MOD11A1 and MYD11A1 MODIS data) values, derived from the Moderate Resolution Imaging Sensor (MODIS) instruments, on-board the Terra and Aqua satellites. MODIS data were downloaded from a NASA server (https://lpdaac.usgs.gov/data_access), imported into GRASS GIS, and temperature values were extracted for each pixel ( $1 \mathrm{~km}$ resolution) where iButton sensors were placed (this figure was produced using data reported in [60]).

Strictly related to the low spatial resolution at which remotely sensed data are acquired, ecotones, i.e., where two macrohabitats intersect, for instance at the edge of a river, between mountains and valleys, green areas in a city or in catch-basins, are not currently well-captured by environmental data. However, ecotones can create microhabitat refugia in a macrohabitat that would otherwise be unsuitable. For example, Hoogstraal demonstrated that in the Nile Valley which is otherwise too dry for ticks, the soft tick Ornithodoros sonrai [Sautet and Witkowski, 1943] was able to colonize rodent burrows close to a permanent river, which provided adequate water and humidity [62]. Research has identified general patterns and mathematical relationships in the "buffering effect" of the physical structure of a microhabitat and has determined that, in general, within the microhabitat experienced by 
the tick, temperature and relative humidity are lower than that of the external environment typically measured for environmental data [63]. However, these patterns are influenced by a variety of factors, including the structure of the microhabitat and surrounding hydrography [63].

\section{Attempting to Overcome the Lack of Microhabitat Data}

Methods to capture, interpret, and produce remotely-sensed data that can be applied to SDMs are continually improving. In March 2019, Planet announced that they can provide satellite imagery from which NDVI can be derived at a resolution of $3-5 \mathrm{~m}$, every 3 days (https://www.planet.com/pulse/ developing-the-worlds-first-indicator-of-forest-carbon-stocks-emissions/). Additionally the project can gain NDVI at $0.8 \mathrm{~m}$ using Light Detecting and Ranging (LiDAR) sensors mounted on aircraft, but for only a single time point due to the costliness of this data collection process. Despite these improvements, there may be a considerable lag time between such data being available and being used in SDMs, which typically require time series data spanning multiple years to truly capture adequate information on the climate. In addition, high resolution data at such a large scale require intense computational power and expertise for use in SDMs, as high resolution satellite data brings with it challenges related to differentiating details between variables within the imagery, as well as new sources of noise [64]. For instance, a project attempted to use NDWI calculated from QuickBird satellite imagery at $2.44 \mathrm{~m}$ spatial resolution to locate potential habitat for invasive mosquitoes (e.g., swimming pools). However, ground truthing of the data showed that shadows cast upon swimming pools by surrounding trees or structures resulted in decreased NDWI values and reduced the ability to detect water bodies [65].

We understand that improving the quality of the remotely sensed data processing chain, including geometric and radiometric corrections, is a complex discipline in itself and takes time and an organized effort. However, we can take better ownership of the data that are currently available to us, and can follow the lead of other disciplines in doing this. A set of Essential Biodiversity Variables (EBV) have been identified to support biodiversity monitoring under the framework of the Group on Earth Observations Biodiversity Observation Network (GEO BON). Out of 21 candidate EBVs suggested by GEO BON, 14 EBVs have been identified as directly or indirectly measurable by remote sensing (https://geobon.org/ebvs/what-are-ebvs/) [66-68]. Two subsets of EBVs, focusing on Species Abundance (SA EBV) and Species Distribution (SD EBV), have been introduced and defined as a space-time-species-gram (cube), which can address species distribution or abundance irrespective of the taxonomy or scale [69]. This classification is facilitated by the availability of global, high-resolution, remotely-sensed data on environmental conditions and ecological species attributes. The framework has been optimized for biodiversity monitoring, but an equivalent product could be developed for relevant data pertaining to invasive species monitoring. Similarly, other areas of research have identified the need for environmental data that better meet the requirements of modelers, and have built high resolution and user friendly databases. For example, Bio-ORACLE (Ocean Rasters for Analysis of Climate and Environment) is a global dataset of environmental data which has been tailored for, and successfully implemented in, the distribution modeling of marine species [70-73]. Creating similar datasets that include environmental (both remotely and proximally sensed) data relevant to IAVP species at a fine spatial scale and a user friendly format could greatly improve the way in which currently available environmental data are used in IAVP SDMs. In addition, online data repositories, that include microhabitat data are available, such as DataONE (Data Observation Network for Earth, https://www.dataone.org/), JaLTER (Japan Long-Term Ecological Research Network; http://db.cger.nies.go.jp/JaLTER/metacat/style/skins/jalter-en/index.jsp) and the VLIZ: IMIS (The Flanders Marine Institute: Integrated Marine Information System, http://www.vliz.be/en/imis for example see [74]). Whilst these databases represent a great resource, people must be made aware that microclimatic data do exist, and centralization of microhabitat data in a well-structured repository could greatly facilitate data dissemination and utilization by the scientific community. 
On a smaller scale, unmanned aerial vehicles (UAVs) and drones can be equipped with visible light, near-infrared, and/or thermal sensors to measure environmental variables, producing NDVI and surface temperature data at high resolution and at the desired scale [75,76]. UAVs have also been used to survey for bird and primate nesting and resting sites to estimate population numbers $[77,78]$, and although this method is not currently suitable for the direct detection of IAVPs, host nesting sites, e.g., woodrat middens, or water bodies suitable for mosquito egg laying, could be surveyed using these techniques and used as a parameter for host availability in SDMs.

Environmental data at the microhabitat level can also be measured using data loggers; small sensors able to measure a range of variables paralleling those that can be remotely sensed, such as temperature, light, air velocity, barometric pressure, and relative humidity (e.g., see HOBO ${ }^{\circledR}$ U30 USB Station (U30-NRC) data logger; Bourne, MA). Many data loggers are small enough to be placed in almost any microhabitat, and can be programmed to record measurements at multiple intervals throughout a $24 \mathrm{~h}$ period. Data derived from such data loggers has been successfully used to model the extirpation and persistence of mammals (American pika, Ochotona princeps [Richardson, 1828]) [79,80] and thermal ecology potentially related to butterfly distribution (Aglais urticae Lepidoptera: Nymphalidae [Linnaeus, 1758], Inachis io Lepidoptera: Nymphalidae [Linnaeus, 1758] and Polygonia c-album, Lepidoptera: Nymphalidae [Linnaeus, 1758]) [81], and could no doubt also be applied to IAVP distributions. While a large number of data loggers need to be employed to collect sufficient data for species distribution modeling, requiring considerable resources to deploy and manage, these data could be supplemented by crowd-sourced means. Environmental data can now be collected from sensors within smart phones that can measure multiple variables, including temperature, pressure, and light, as well as from privately owned amateur weather stations and apps that ask citizens to report climatic data, such as amount of precipitation [82].

Despite the generalized application of coarse resolution data for modeling the distribution of IAVPs, overcoming the lack of data at a microhabitat scale has been attempted, although not necessarily for SDMs. An alternative and empirical strategy to improve our understanding of microhabitat thermal properties can be in the implementation of controlled experiments, that allow us to characterize microhabitat properties $[83,84]$. For example, studies have directly measured temperature within aquatic mosquito egg laying sites [48], and have recorded environmental variables in catch basins known to be egg laying sites for Ae. albopictus in Italy [58]. Both studies found that modeling mosquito population dynamics using these variables, rather than air temperature which is typically used, changes, and likely improves, the estimated development of the mosquito. An increasing number of scientific studies call for a better estimation of the thermal characteristics of mosquito microhabitats, specifically in order to achieve more reliable SDMs $[48,58,85]$.

The strategies to overcome the lack of microhabitat data proposed above require intense use of resources, and we propose that microhabitat data collected by data loggers, crowd-sourcing, unmanned aerial vehicles, and/or controlled environmental studies are maintained in a database which can be freely contributed to, and be used by all those studying IAVP ecology. An open access database of microhabitat data could greatly facilitate the propagation of both collection and use of this type of environmental data.

\section{Conclusions}

Currently, environmental data that is used to inform ecological niche models largely relies on remotely sensed data, which is at a relatively course temporal and spatial resolution and does not accurately represent the microhabitat experienced by the species of interest, nor that at which activities informed by the prediction are executed. The predicted distribution of invasive arthropods resulting from models are therefore likely to be insufficient for direct application. The subsequent over- and/or under-estimations in IAVP distribution can have considerable consequences on control efforts, which may be informed by such predictions. We posit that consequently, efficiency and efficacy in the allocation of resources to control IAVPs are sub-optimal. The optimal resolution of environmental 
data relevant to IAVP ecology will likely vary according to the species under consideration, but we assume that this resolution will typically be $<1 \mathrm{~m}$ and hourly. The scientific community may be far from having, for example, remotely-sensed measured temperature data at a $1 \mathrm{~m}$ spatial resolution or hourly temporal resolution for large extensions. However, we argue that any effort to improve the availability of data at a finer resolution than currently available will be of great benefit for modeling the distribution, abundance, or demographic rates of IAVP species. In the meantime we encourage modelers and ecologists to take a proactive approach in collecting fine resolution data using data loggers, crowd-sourcing, unmanned aerial vehicles and/or controlled environmental studies. We propose that these proximally-sensed data, as well as remotely-sensed data, be made open access in a user friendly database. We also hope that the suggestions made here for overcoming issues in environmental data for modeling IAVP distributions can be adapted and applied to species distribution modeling in other areas of research.

Author Contributions: Conceptualization, E.L.P. and M.M.; investigation, E.L.P., S.P., and M.M.; resources, E.L.P., S.P., D.R., and M.M.; formal analysis, M.M.; data curation, M.M.; Writing-Original Draft preparation, E.L.P., S.P., D.R., and M.M.; Writing-Review and Editing, E.L.P., S.P., and M.M.; visualization, E.L.P. and M.M.; supervision, M.M.; project administration, E.L.P.

Funding: E.L.P. and M.M. acknowledge funding support from the Pacific Southwest Regional Center of Excellence for Vector-Borne Diseases funded by the U.S. Centers for Disease Control and Prevention (Cooperative Agreement U01CK000516). M.M. also acknowledges funding from the National Aeronautics and Space Administration's Applied Sciences Program in Health and Air Quality (Grant NNX15AF36G).

Conflicts of Interest: The authors declare no conflict of interest.

\section{References}

1. Dukes, J.S.; Mooney, H.A. Does global change increase the success of biological invaders? Trends Ecol. Evol. 1999, 14, 135-139. [CrossRef]

2. Pyšek, P.; Richardson, D.M. Invasive species, environmental change and management, and health. Annu. Rev. Environ. Resour. 2010, 35, 25-55. [CrossRef]

3. Charles, H.; Dukes, J.S. Impacts of Invasive Species on Ecosystem Services. In Biological Invasions; Ecological Studies, Nentwig, W., Eds.; Springer: Berlin/Heidelberg, Germany, 2007; pp. 217-237, ISBN 978-3-540-36920-2.

4. U.S. Fish and Wildlife Services. The Cost of Invasive Species. 2012. Available online: https://www.fws.gov/ verobeach/pythonpdf/costofinvasivesfactsheet.pdf (accessed on 20 February 2019).

5. Baly, A.; Toledo, M.E.; Lambert, I.; Benítez, E.; Rodriguez, K.; Rodriguez, E.; Vanlerberghe, V.; der Stuyft, P.V.; Baly, A.; Toledo, M.E.; et al. Cost of intensive routine control and incremental cost of insecticide-treated curtain deployment in a setting with low Aedes aegypti infestation. Rev. Soc. Bras. Med. Trop. 2016, 49, 418-424. [CrossRef]

6. Oreska, M.P.J.; Aldridge, D.C. Estimating the financial costs of freshwater invasive species in Great Britain: A standardized approach to invasive species costing. Biol. Invasions 2011, 13, 305-319. [CrossRef]

7. Grard, G.; Caron, M.; Mombo, I.M.; Nkoghe, D.; Mboui Ondo, S.; Jiolle, D.; Fontenille, D.; Paupy, C.; Leroy, E.M. Zika virus in Gabon (central Africa) -2007: A new threat from Aedes albopictus? PLoS Negl. Trop. Dis. 2014, 8, e2681. [CrossRef]

8. Rainey, T.; Occi, J.L.; Robbins, R.G.; Egizi, A. Discovery of Haemaphysalis longicornis (Ixodida: Ixodidae) parasitizing a sheep in New Jersey, United States. J. Med. Entomol. 2018, 55, 757-759. [CrossRef]

9. Robles, N.J.C.; Han, H.J.; Park, S.-J.; Choi, Y.K. Epidemiology of severe fever and thrombocytopenia syndrome virus infection and the need for therapeutics for the prevention. Clin. Exp. Vaccine Res. 2018, 7, 43-50. [CrossRef]

10. Sanders, C.J.; Mellor, P.S.; Wilson, A.J. Invasive arthropods. Rev. Sci. Tech. 2010, 29, 273-286. [CrossRef]

11. Simberloff, D. How much information on population biology is needed to manage introduced species? Conserv. Biol. 2003, 17, 83-92. [CrossRef]

12. Malanson, G.P.; Walsh, S.J. A Geographical Approach to Optimization of Response to Invasive Species. In Science and Conservation in the Galapagos Islands: Frameworks \& Perspectives; Social and Ecological Interactions 
in the Galapagos Islands, Walsh, S.J., Mena, C.F., Eds.; Springer: New York, NY, USA, 2013; pp. 199-215, ISBN 978-1-4614-5794-7.

13. Carter, G.A.; Lucas, K.L.; Blossom, G.A.; Lassitter, C.L.; Holiday, D.M.; Mooneyhan, D.S.; Fastring, D.R.; Holcombe, T.R.; Griffith, J.A. Remote sensing and mapping of tamarisk along the Colorado River, USA: A comparative use of summer-acquired hyperion, Thematic Mapper and QuickBird Data. Remote Sens. 2009, 1,318-329. [CrossRef]

14. Rocchini, D.; Boyd, D.S.; Féret, J.-B.; Foody, G.M.; He, K.S.; Lausch, A.; Nagendra, H.; Wegmann, M.; Pettorelli, N. Satellite remote sensing to monitor species diversity: Potential and pitfalls. Remote Sens. Ecol. Conserv. 2015, 2, 25-36. [CrossRef]

15. Eklundh, L.; Johansson, T.; Solberg, S. Mapping insect defoliation in Scots pine with MODIS time-series data. Remote Sens. Environ. 2009, 113, 1566-1573. [CrossRef]

16. Jepsen, J.U.; Hagen, S.B.; Høgda, K.A.; Ims, R.A.; Karlsen, S.R.; Tømmervik, H.; Yoccoz, N.G. Monitoring the spatio-temporal dynamics of geometrid moth outbreaks in birch forest using MODIS-NDVI data. Remote Sens. Environ. 2009, 113, 1939-1947. [CrossRef]

17. GrrlScientist. Massive Swarm of Ladybugs Detected by California Weather Radar. Forbes. 2019. Available online: https://www.forbes.com/sites/grrlscientist/2019/06/10/160-square-mile-swarm-of-ladybugsdetected-by-california-weather-radar/\#54ac52054d64 (accessed on 7 August 2019).

18. Nansen, C. The potential and prospects of proximal remote sensing of arthropod pests. Pest Manag. Sci. 2016, 72, 653-659. [CrossRef]

19. Rey, B.; Aleixos, N.; Cubero, S.; Blasco, J. Xf-Rovim. A field robot to detect olive trees infected by Xylella fastidiosa using proximal sensing. Remote Sens. 2019, 11, 221. [CrossRef]

20. Dunn, A.M.; Hatcher, M.J. Parasites and biological invasions: Parallels, interactions, and control. Trends Parasitol. 2015, 31, 189-199. [CrossRef]

21. Elith, J.; Graham, C.H. Do they? How do they? WHY do they differ? On finding reasons for differing performances of species distribution models. Ecography 2009, 32, 66-77. [CrossRef]

22. Shabani, F.; Kumar, L. Should species distribution models use only native or exotic records of existence or both? Ecol. Inform. 2015, 29, 57-65. [CrossRef]

23. Gutierrez, A.P.; Ponti, L.; Dalton, D.T. Analysis of the invasiveness of spotted wing Drosophila (Drosophila suzukii) in North America, Europe, and the Mediterranean Basin. Biol. Invasions 2016, 18,3647-3663. [CrossRef]

24. Proestos, Y.; Christophides, G.K.; Ergüler, K.; Tanarhte, M.; Waldock, J.; Lelieveld, J. Present and future projections of habitat suitability of the Asian tiger mosquito, a vector of viral pathogens, from global climate simulation. Philos. Trans. R. Soc. B 2015, 370, 20130554. [CrossRef]

25. Lobo, J.M.; Jiménez-Valverde, A.; Hortal, J. The uncertain nature of absences and their importance in species distribution modelling. Ecography 2010, 33, 103-114. [CrossRef]

26. Cord, A.F.; Meentemeyer, R.K.; Leitão, P.J.; Václavík, T. Modelling species distributions with remote sensing data: Bridging disciplinary perspectives. J. Biogeogr. 2013, 40, 2226-2227. [CrossRef]

27. Hay, S.I. An overview of remote sensing and geodesy for epidemiology and public health application. Adv. Parasitol. 2000, 47, 1-35.

28. Kyba, C.C.M.; Garz, S.; Kuechly, H.; De Miguel, A.S.; Zamorano, J.; Fischer, J.; Hölker, F. High-resolution imagery of Earth at night: New sources, opportunities and challenges. Remote Sens. 2015, 7, 1-23. [CrossRef]

29. Elvidge, C.; Baugh, K.; Hobson, V.; Kihn, E.; Kroehl, H.; Davis, E.; Cocero, D. Satellite inventory of human settlements using nocturnal radiation emissions: A contribution for the global toolchest. Glob. Chang. Biol. 1997, 3, 387-395. [CrossRef]

30. Marcantonio, M.; Rizzoli, A.; Metz, M.; Rosà, R.; Marini, G.; Chadwick, E.; Neteler, M. Identifying the environmental conditions favouring West Nile virus outbreaks in Europe. PLoS ONE 2015, 10, e0121158. [CrossRef]

31. Pareeth, S.; Salmaso, N.; Adrian, R.; Neteler, M. Homogenised daily lake surface water temperature data generated from multiple satellite sensors: A long-term case study of a large sub-Alpine lake. Sci. Rep. 2016, 6, 31251. [CrossRef]

32. Metz, M.; Andreo, V.; Neteler, M. A new fully gap-free time series of land surface temperature from MODIS LST data. Remote Sens. 2017, 9, 1333. [CrossRef] 
33. European Environment Agency Copernicus Land Monitoring Service-Corine Land Cover. Available online: https://www.eea.europa.eu/data-and-maps/data/copernicus-land-monitoring-service-corine (accessed on 20 August 2019).

34. Land Monitoring Service CORINE Land Cover-Copernicus Land Monitoring Service. Available online: https://land.copernicus.eu/pan-european/corine-land-cover (accessed on 20 August 2019).

35. Yang, L.; Jin, S.; Danielson, P.; Homer, C.; Gass, L.; Bender, S.M.; Case, A.; Costello, C.; Dewitz, J.; Fry, J.; et al. A new generation of the United States National Land Cover Database: Requirements, research priorities, design, and implementation strategies. ISPRS J. Photogramm. Remote Sens. 2018, 146, 108-123. [CrossRef]

36. Friedl, M.A.; Sulla-Menashe, D.; Tan, B.; Schneider, A.; Ramankutty, N.; Sibley, A.; Huang, X. MODIS Collection 5 global land cover: Algorithm refinements and characterization of new datasets. Remote Sens. Environ. 2010, 114, 168-182. [CrossRef]

37. Fick, S.E.; Hijmans, R.J. WorldClim 2: New 1-km spatial resolution climate surfaces for global land areas. Int. J. Climatol. 2017, 37, 4302-4315. [CrossRef]

38. Hijmans, R.J.; Cameron, S.E.; Parra, J.L.; Jones, P.G.; Jarvis, A. Very high resolution interpolated climate surfaces for global land areas. Int. J. Climatol. 2005, 25, 1965-1978. [CrossRef]

39. Jarnevich, C.S.; Reynolds, L.V. Challenges of predicting the potential distribution of a slow-spreading invader: A habitat suitability map for an invasive riparian tree. Biol. Invasions 2011, 13, 153-163. [CrossRef]

40. Kreakie, B.J.; Fan, Y.; Keitt, T.H. Enhanced migratory waterfowl distribution modeling by inclusion of depth to water table data. PLoS ONE 2012, 7, e30142. [CrossRef]

41. Pascoe, E.L.; Marcantonio, M.; Caminade, C.; Foley, J.E. Modeling potential habitat for Amblyomma tick species in California. Insects 2019, 10, 201. [CrossRef]

42. Cornes, R.C.; van der Schrier, G.; van den Besselaar, E.J.M.; Jones, P.D. An ensemble version of the E-OBS temperature and precipitation data sets. J. Geophys. Res. Atmos. 2018, 123, 9391-9409. [CrossRef]

43. Bedia, J.; Herrera, S.; Gutiérrez, J.M. Dangers of using global bioclimatic datasets for ecological niche modeling. Limitations for future climate projections. Glob. Planet. Chang. 2013, 107, 1-12. [CrossRef]

44. Hofstra, N.; Haylock, M.; New, M.; Jones, P.; Frei, C. Comparison of six methods for the interpolation of daily, European climate data. J. Geophys. Res. Atmos. 2008, 113, D21. [CrossRef]

45. Center for Diseases Control and Prevention (CDC). ESTIMATED Potential Range of Aedes aegypti and Aedes albopictus in the United States, 2017; CDC: Atlanta, GA, USA, 2018.

46. Rose, R.I. Pesticides and public health: Integrated methods of mosquito management. Emerg. Infect. Dis. 2001, 7, 17-23. [CrossRef] [PubMed]

47. Born, W.; Rauschmayer, F.; Bräuer, I. Economic evaluation of biological invasions-A survey. Ecol. Econ. 2005, 55, 321-336. [CrossRef]

48. Paaijmans, K.P.; Imbahale, S.S.; Thomas, M.B.; Takken, W. Relevant microclimate for determining the development rate of malaria mosquitoes and possible implications of climate change. Malar. J. 2010, 9, 196. [CrossRef] [PubMed]

49. Schulze, T.L.; Jordan, R.A.; Hung, R.W. Effects of microscale habitat physiognomy on the focal distribution of Ixodes scapularis and Amblyomma americanum (Acari: Ixodidae) nymphs. Environ. Entomol. 2002, 31, 1085-1090. [CrossRef]

50. Beck-Johnson, L.M.; Nelson, W.A.; Paaijmans, K.P.; Read, A.F.; Thomas, M.B.; Bjørnstad, O.N. The importance of temperature fluctuations in understanding mosquito population dynamics and malaria risk. R. Soc. Open Sci. 2017, 4, 160969. [CrossRef] [PubMed]

51. Gray, J.S.; Estrada-Peña, A.; Vial, L. Ecology of nidicolous ticks. In Biology of Ticks; Oxford University Press: Oxford, UK, 2014; Volume 2, pp. 39-60.

52. Burks, C.S.; Stewart, R.L.; Needham, G.R.; Lee, R.E. The role of direct chilling injury and inoculative freezing in cold tolerance of Amblyomma americanum, Dermacentor variabilis and Ixodes scapularis. Physiol. Entomol. 1996, 21, 44-50. [CrossRef]

53. Yoder, J.A.; Tank, J.L. Similarity in critical transition temperature for ticks adapted for different environments: Studies on the water balance of unfed ixodid larvae. Int. J. Acarol. 2006, 32, 323-329. [CrossRef]

54. Allingham, P.G. Effect of temperature on late immature stages of Culicoides brevitarsis (Diptera: Ceratopogonidae). J. Med. Entomol. 1991, 28, 878-881. [CrossRef] [PubMed]

55. Zellweger, F.; De Frenne, P.; Lenoir, J.; Rocchini, D.; Coomes, D. Advances in microclimate ecology arising from remote sensing. Trends Ecol. Evol. 2019, 34, 327-341. [CrossRef] [PubMed] 
56. Chabot-Couture, G.; Nigmatulina, K.; Eckhoff, P. An environmental data set for vector-borne disease modeling and epidemiology. PLoS ONE 2014, 9, e94741. [CrossRef] [PubMed]

57. Vancutsem, C.; Ceccato, P.; Dinku, T.; Connor, S.J. Evaluation of MODIS land surface temperature data to estimate air temperature in different ecosystems over Africa. Remote Sens. Environ. 2010, 114, 449-465. [CrossRef]

58. Vallorani, R.; Angelini, P.; Bellini, R.; Carrieri, M.; Crisci, A.; Zeo, S.M.; Messeri, G.; Venturelli, C. Temperature characterization of different urban microhabitats of Aedes albopictus (Diptera Culicidae) in Central-Northern Italy. Environ. Entomol. 2015, 44, 1182-1192. [CrossRef]

59. Becker, N. Mosquitoes and Their Control; Springer: Berlin/Heidelberg, Germany; London, UK, 2010; ISBN 978-3-540-92874-4.

60. Marcantonio, M. Environmental Modelling and Spatial Ecology with Focus on Invasive Aedes Mosquitoes and Emergent Mosquito-Borne Pathogens. Ph.D. Thesis, Technische Universität Berlin, Berlin, Germany, 2017.

61. Yee, D.A. Thirty years of Aedes albopictus (Diptera: Culicidae) in America: An introduction to current perspectives and future challenges. J. Med. Entomol. 2016, 53, 989-991. [CrossRef]

62. Hoogstraal, H. A Preliminary, Annotated list of ticks (Ixodoidea) of the Anglo-Egyptian Sudan. J. Parasitol. 1954, 40, 304. [CrossRef]

63. Vial, L. Biological and ecological characteristics of soft ticks (Ixodida: Argasidae) and their impact for predicting tick and associated disease distribution. Parasite 2009, 16, 191-202. [CrossRef] [PubMed]

64. Nagendra, H.; Rocchini, D. High resolution satellite imagery for tropical biodiversity studies: The devil is in the detail. Biodivers. Conserv. 2008, 17, 3431. [CrossRef]

65. McFeeters, S.K. Using the normalized difference water index (NDWI) within a geographic information system to detect swimming pools for mosquito abatement: A practical approach. Remote Sens. 2013, 5, 3544-3561. [CrossRef]

66. O'Connor, B.; Secades, C.; Penner, J.; Sonnenschein, R.; Skidmore, A.; Burgess, N.D.; Hutton, J.M. Earth observation as a tool for tracking progress towards the Aichi Biodiversity Targets. Remote Sens. Ecol. Conserv. 2015, 1, 19-28. [CrossRef]

67. Schmeller, D.S.; Weatherdon, L.V.; Loyau, A.; Bondeau, A.; Brotons, L.; Brummitt, N.; Geijzendorffer, I.R.; Haase, P.; Kuemmerlen, M.; Martin, C.S.; et al. A suite of essential biodiversity variables for detecting critical biodiversity change. Biol. Rev. 2018, 93, 55-71. [CrossRef] [PubMed]

68. Vihervaara, P.; Auvinen, A.-P.; Mononen, L.; Törmä, M.; Ahlroth, P.; Anttila, S.; Böttcher, K.; Forsius, M.; Heino, J.; Heliölä, J.; et al. How Essential Biodiversity Variables and remote sensing can help national biodiversity monitoring. Glob. Ecol. Conserv. 2017, 10, 43-59. [CrossRef]

69. Jetz, W.; McGeoch, M.A.; Guralnick, R.; Ferrier, S.; Beck, J.; Costello, M.J.; Fernandez, M.; Geller, G.N.; Keil, P.; Merow, C.; et al. Essential biodiversity variables for mapping and monitoring species populations. Nat. Ecol. Evol. 2019, 3, 539. [CrossRef] [PubMed]

70. Bridge, T.; Beaman, R.; Done, T.; Webster, J. Predicting the location and spatial extent of submerged coral reef habitat in the Great Barrier Reef World Heritage Area, Australia. PLoS ONE 2012, 7, e48203. [CrossRef] [PubMed]

71. Jueterbock, A.; Tyberghein, L.; Verbruggen, H.; Coyer, J.A.; Olsen, J.L.; Hoarau, G. Climate change impact on seaweed meadow distribution in the North Atlantic rocky intertidal. Ecol. Evol. 2013, 3, 1356-1373. [CrossRef] [PubMed]

72. Quillfeldt, P.; Masello, J.F.; Navarro, J.; Phillips, R.A. Year-round distribution suggests spatial segregation of two small petrel species in the South Atlantic. J. Biogeogr. 2013, 40, 430-441. [CrossRef]

73. Tyberghein, L.; Verbruggen, H.; Pauly, K.; Troupin, C.; Mineur, F.; De Clerck, O. Bio-ORACLE: A global environmental dataset for marine species distribution modelling: Bio-ORACLE marine environmental data rasters. Glob. Ecol. Biogeogr. 2012, 21, 272-281. [CrossRef]

74. Guden, R.M.E.; Vafeiadou, A.M.; De Meester, N.; Derycke, S.; Moens, T. Relative Abundance Data of 4 Cryptic Lineages of the Nematode Litoditis Marina in a Saltmarsh Habitat in the Western-Scheldt Estuary; The Flanders Marine Institute: Integrated Marine Information System: London, UK, 2018.

75. Díaz-Delgado, R.; Ónodi, G.; Kröel-Dulay, G.; Kertész, M. Enhancement of ecological field experimental research by means of UAV multispectral sensing. Drones 2019, 3, 7. [CrossRef] 
76. Harvey, M.C.; Rowland, J.V.; Luketina, K.M. Drone with thermal infrared camera provides high resolution georeferenced imagery of the Waikite geothermal area, New Zealand. J. Volcanol. Geotherm. Res. 2016, 325, 61-69. [CrossRef]

77. Afán, I.; Máñez, M.; Díaz-Delgado, R. Drone monitoring of breeding waterbird populations: The case of the Glossy ibis. Drones 2018, 2, 42. [CrossRef]

78. Bonnin, N.; Van Andel, A.C.; Kerby, J.T.; Piel, A.K.; Pintea, L.; Wich, S.A. Assessment of chimpanzee nest detectability in drone-acquired images. Drones 2018, 2, 17. [CrossRef]

79. Wilkening, J.L.; Ray, C.; Beever, E.A.; Brussard, P.F. Modeling contemporary range retraction in Great Basin pikas (Ochotona princeps) using data on microclimate and microhabitat. Quat. Int. 2011, 235, 77-88. [CrossRef]

80. Beever, E.A.; Ray, C.; Mote, P.W.; Wilkening, J.L. Testing alternative models of climate-mediated extirpations. Ecol. Appl. 2010, 20, 164-178. [CrossRef]

81. Bryant, S.R.; Thomas, C.D.; Bale, J.S. The influence of thermal ecology on the distribution of three nymphalid butterflies. J. Appl. Ecol. 2002, 39, 43-55. [CrossRef]

82. Muller, C.L.; Chapman, L.; Johnston, S.; Kidd, C.; Illingworth, S.; Foody, G.; Overeem, A.; Leigh, R.R. Crowdsourcing for climate and atmospheric sciences: Current status and future potential. Int. J. Climatol. 2015, 35, 3185-3203. [CrossRef]

83. Thomas, S.M.; Obermayr, U.; Fischer, D.; Kreyling, J.; Beierkuhnlein, C. Low-temperature threshold for egg survival of a post-diapause and non-diapause European aedine strain, Aedes albopictus (Diptera: Culicidae). Parasites Vectors 2012, 5, 100. [CrossRef] [PubMed]

84. Watt, J.H.; van den Berg, S. Chapter 15. Semi-Controlled Environments: Field Research. In Research Methods for Communication Science; Allyn \& Bacon: Boston, MA, USA, 2002; pp. 227-241.

85. Asare, E.O.; Tompkins, A.M.; Amekudzi, L.K.; Ermert, V. A breeding site model for regional, dynamical malaria simulations evaluated using in situ temporary ponds observations. Geospat. Health 2016, 11, 390. [CrossRef] [PubMed]

(C) 2019 by the authors. Licensee MDPI, Basel, Switzerland. This article is an open access article distributed under the terms and conditions of the Creative Commons Attribution (CC BY) license (http://creativecommons.org/licenses/by/4.0/). 